\title{
Matrimonios y algo más. Discurso eugénico en torno al proceso de selección de pareja. El caso de la revista Viva Cien Años. 1935-1947
}

\section{Marriages and more. Eugenic discourse on mate selecting process. The case of Viva Cien Años magazine, 1935-1947}

Luciana Linares

Universidad Nacional de Mar del Plata Centro de Estudios Históricos Grupo de investigación de Historia Social Argentina (Argentina) lume_linares@hotmail.com

El presente artículo tiene como objetivo principal, abordar la cuestión del proceso de selección,jerarquización y clasificación propuesto por la eugenesia como disciplina científica vigente en el país durante la década del treinta. Para ello, analizaremos los mecanismos de construcción discursiva por los cuales desde un medio de comunicación con amplia difusión (el caso de la revista Viva Cien Años), se aconseja acerca del "deber ser" de las parejas a la hora de formar matrimonios. Veremos de qué manera se establece una intertextualidad entre discursos variados -como es el caso del discurso médico, académico, político, religiosos, etc.- que se encausan en una especie de receta a seguir para elegir al cónyuge correcto. La discusión que subyace estos mecanismos, que intentan persuadir principalmente a las mujeres, se basa en la búsqueda de la mejora racial y la optimización de caracteres heredables, haciendo de esto parte del "deber para con la Patria". Estas cuestiones actuaron como la columna vertebral de un discurso arraigado en la idea de pueblo sano y fuerte. Discurso que eugenistas y distintos profesionales tomaron e intentaron difundir, con un objetivo pedagógico, por un lado y preventivo por otro.

Palabras Clave: Eugenesia - Matrimonio - Pareja - Selección 


\begin{abstract}
The main objective of this article, addresses the issue of selecting, ranking and classifying mates proposed by eugenics as a scientific discipline during the thirties in Argentina. In order to achieve this, we analyze the mechanisms of discursive construction from a wide circulation media (the case of the Viva Cien Años magazine) which advised about forming marriages. We will see how an intertextuality is stablished between several discourses -as is the case of medical discourse , academic, political, religious , etc.-, that bring to follow a kind of recipe in order to choose the right partner. The argument underlying these mechanisms , trying to persuade mostly women, is based on the pursuit of racial improvement and the optimization of heritable characteristics, as a part of the " duty to the Fatherland.". These issues served as the backbone of a discourse rooted in the ideal of healthy and strong people, which the eugenicists and other professionals took and tried to spread. according to their pedagogical objective, on the one hand and their preventive objective, on the other.
\end{abstract}

Key Words: Eugenics - Marriage - Couple - Selection

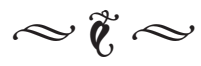

\section{A modo de introducción}

Hacia la década de 1910 y hasta mediados del siglo $\mathrm{XX}$, se desarrollaron ideologías y corrientes científicas -para ellas dispuestasque propusieron la idea de mejoramiento racial para un pueblo sano y fuerte. La eugenesia como disciplina surgió en Inglaterra de la mano de Sir Francis Galton, hacia finales del siglo XIX. ${ }^{1}$ Como "ciencia del buen nacer"

1. Al hablar de "eugenesia", adscribimos a la definición de la misma, esbozada por Héctor Palma, quien sostiene que "consiste en implementar medidas para el mejoramiento de la descendencia humana, posibilitando la reproducción diferencial de ciertos individuos o grupos considerados valiosos o mejores, constituyó un entramado de saberes y tecnologías sumamente extendido e influyente en la primera mitad del siglo XX pero que con algunas variaciones persiste hasta la actualidad." PALMA, Héctor, "Consideraciones historiográficas, epistemológicas y prácticas acerca de la eugenesia”, en MIRANDA, Marisa y VALLEJO, Gustavo (compiladores) Darwinismo social interesó a profesionales, académicos y políticos y para la primera década del siglo XX, contaba con una amplia red de instituciones a nivel mundial que se planteaban la eugenesia como respuesta a la cuestión social del momento. Congresos, conferencias y circulación de académicos por distintos puntos de Europa y América, actuaron como contexto en el que se dieron un sinfín de influencias mutuas. De Galton hasta llegar a Nicola Pende y Renato Kehl, la eugenesia iba tomando fuerza entre académicos y políticos. Mencionaremos aquí la existencia para estas coordenadas espaciotemporales de la Argentina de primera mitad del siglo XX, de una especie de hibridación teórica y adaptación de la corriente de pensamiento a las cuestiones poblacionales,

y eugenesia en el mundo latino, Siglo Veintiuno, Buenos Aires, 2005, p. 115. 
culturales y sanitarias del país. ${ }^{2}$ Esta fuerte influencia en los profesionales de la salud se produjo también en otras latitudes, fuera del contexto europeo. Un ejemplo de ello, fueron México y Brasil, donde también tuvieron una masiva aceptación este cuerpo de ideas y muchas de las iniciativas de los eugenistas se tradujeron en políticas públicas en función de las características poblacionales, siendo que "a través de la eugenesia, se integraron el género y la raza en la política de identidad nacional". ${ }^{3}$

En este contexto de influencias y crecimiento de las redes internacionales de eugenesia, un grupo de profesionales de la salud, que provenían en su mayoría del campo académico, buscaron mecanismos de difusión de la propaganda eugénica. Su objetivo radicaba en llevar la teoría eugenésica al común de la población utilizando para ello, los medios de comunicación masivos delaépoca,comola radio y las revistas. Con distintos apoyos comerciales y políticos desarrollaron una publicación que se postuló como de "divulgación popular de la ciencia”. De esta manera, los doctores Arturo León López, Mariano Barilari y Godfredo Grasso fundaron la revista Viva Cien Años (VCA) en $1934 .{ }^{4}$ De carácter celebratorio,

2. Así lo plantea la Dra. Marisa Miranda al profundizar acerca del lugar que la Argentina tuvo en el plano internacional, referido a la eugenesia y sus redes de influencia. MIRANDA, Marisa, "La Argentina en el escenario eugénico internacional" en MIRANDA, Marisa y VALLEJO, Gustavo (directores) Una Historia de la eugenesia. Argentina y las redes biopoliticas internacionales. 1912-1945, Biblos, Buenos Aires, 2012.

3. STEPAN, Nancy, A hora da Eugenia. Raça, género y nación no America Latina, Fiocruz, Río de Janeiro, 1991, p. 105

4. Estos tres profesionales de la salud se desempeñaban en el ámbito no solo médico sino también académico de la Universidad de Buenos Aires. Con sus tesis publicadas con el aval de la Facultad de Medicina, la medicina presentada en la publicación se proponía como la única manera de canalizar las problemáticas sociales y dar respuesta a través de la cultura eugénica y la medicina preventiva, a las cuestiones vinculadas a la salud de la población. Cabe mencionar, que ya el higienismo, bien arraigado en el país para finales del siglo XIX y principios del XX, había puesto en la agenda la preocupación racial y por la descendencia. Sin embargo, fue la eugenesia la que se declamaba como ciencia moderna capaz de transformar los destinos de los pueblos. Así, la revista Viva Cien Años se presentaba como un agente de difusión de la propaganda eugénica a partir de mecanismos variados. Por un lado, la coherencia entre propaganda y publicidad comercial, siendo que ésta última se encontraba a disposición de la primera. Por otro lado, las claras líneas editoriales y secciones que mencionaban, una y otra vez, la importancia de repensar y reeducar al pueblo, en la misma dirección que las gráficas y las cartas de lectores. Todas las partes de la publicación fueron dispuestas en función de un claro objetivo: difundir el ideario eugenésico.

Elapoyo económico que obtuvolapublicación provino, en principio, de laboratorios que buscaban colocar sus productos en el mercado local (como el caso de los laboratorios Bayer, que funcionaban desde 1911 en el país bajo la razón social Federico Bayer y Compañía), así

integraban parte de los cuerpos directivos y de gestión de muchas de las instituciones de salud mencionadas, que cobraban importancia en el contexto de la Argentina de los años treinta. Así también, tenían experiencia en divulgación científica, publicando artículos en revistas prestigiosas en el ambiente académico como La semana Médica, la Revista del Instituto Nacional de Bacteriología del Departamento Nacional de Higiene, La tribuna médica, Anales de Biotipología, Eugenesia y medicina social (ABEMS), entre otras publicaciones. 
como marcas que vinculaban sus productos $y$ servicios con cuestiones de higiene y salud o a la necesidad de modernizar el hogar. Entre ellas se encontraban, las empresas Philips, Williams Química \& técnica, C.A.D.E (Compañía Argentina de electricidad S.A), Royal, Garfield, YPF, Olivetti, OSRAM, Fravega, etc. Más allá de la pauta comercial que auspiciaba la publicación, contó con auspicios institucionales que entendemos también como avales de reconocidas instituciones referidas a salud tanto a nivel nacional como continental. Cabe aquí mencionar, que los mismos se encontraban en la primera página de la revista, con un destaque en rojo y central. En ese sentido, es posible mencionar, entre otras, a la Asistencia Pública de Buenos Aires, la Asociación Médica Argentina, la Asociación Médica de Kinesiología, el Ateneo Argentino de Educación Física,el Departamento Nacional de Higiene, la Liga Argentina de Higiene Mental, Museo Social Argentino. Además de ese resaltado al principio de la publicación, en ocasiones aparecían publicitados en el cuerpo de la revista muchas de sus actividades y convocatorias, llegando a tomar mitad de página impar en la misma. Esta lista de avales y auspicios, ponía de manifiesto la circulación de los profesionales que fundaron la revista, así como el interés institucional en generar una publicación "popular" de medicina y salud.

Viva Cien Años estaba dirigida al público en general y se proponía como una "publicación de orientación y divulgación científicohigiénica esencialmente popular." ${ }^{5} \mathrm{Si}$ bien no hemos accedido a información sobre la tirada de la misma, analizando la convocatoria realizada a la hora de las suscripciones para

5. Este slogan está presente en la última línea de la página uno impar de todas las ediciones de la publicación. 92 lectores, observamos que estaba presente en provincias como Córdoba, Santa Fe y Mendoza, lugares donde se propagaba rápidamente el consumo editorial. ${ }^{6}$ En cuanto al público lector, se dirigía hacia los sectores alfabetizados que participaban de este mercado de consumo editorial, presentándose como una "revista popular de salud". Considerando sus mecanismos de construcción discursiva, se advierte que los profesionales de la salud trabajaban en sus artículos tratando de llevar los términos propios de la medicina a un lenguaje accesible, a través de ejemplos, historias, moralejas y escenas de la vida cotidiana. Asimismo, la estructura de esos mensajes establecían una especie de dialogo médico-paciente, a partir del consejo. ${ }^{7}$

Así, la publicación creció y dio lugar a la conformación de un sello editorial desde el cual se publicaban libros y otras revistas de salud orientadas a la educación eugenésica. Más tarde, desde este sello surgieron programas de radio, que iban desde la cálida recomendación médica hasta clases de gimnasia en vivo.

Si bien se mencionaban de manera constante la preocupación y el rol del hombre en la

6. Como bien lo describen en sus trabajos sobre la cuestión editorial en el país SIDICARO, Ricardo, La política mirada desde arriba. Las ideas del diario La Nación. 1909- 1989. Sudamericana, Buenos Aires,1994; GUTIERREZ, Leandro y ROMERO, Luis Alberto, Sectores populares, cultura y política, Sudamericana, Buenos Aires, 1995 ; DE DIEGO, José Luis (director) Editores y politicas editoriales en Argentina (1880-2000), Fondo de Cultura Económica, Buenos Aires, 2006.

7. Dichas cuestiones son profundizadas en la tesis de maestría, de la cual se desprende este trabajo. LINARES, Luciana, Delineando los cuerpos. Construcciones discursivas en torno a la mujer a través de la propaganda eugénica en Argentina. El caso de la publicación Viva Cien Años. 19351947, Tesis de Maestría, Universidad Nacional de Mar del Plata, 2014. 
sociedad, la revista planteaba que "la mujer" era el sujeto clave para la eugenesia, por ser ella la articuladora y sujeto clave a la hora de modificar prácticas culturales en el hogar. "La mujer" tuvo para $V C A$ un papel esencial a la hora de pensar la eugenesia en el país. En este ideario, "la mujer" era vista como problema y como medio para construir al "ciudadano eugénico". De allí, la preocupación primordial por acercarle a las lectoras las pautas de reconocimiento de parejas eugenicamente deseables, para formar matrimonios aptos. En la decisión de las mujeres radicaba, para los eugenistas, el camino hacia un pueblo sano.

\section{La receta perfecta. Elegir pareja y formar el matrimonio.}

Durante las décadas del '20,'30 y'40, tanto en los congresos como en las distintas redes de eugenistas a nivel internacional, se discutía fervientemente acerca del matrimonio, los peligros venéreos y el papel de "la mujer" en el nuevo contexto de inserción laboral en el período de entreguerras. Las ideas de raza y nación impregnaban el pensamiento político de la época y la eugenesia otorgaba respuestas a estos interrogantes.

La "familia" fue la preocupación de las elites dirigentes a lo largo del siglo XX, en América Latina, que se sumaba a este clima de ideas mundial acerca de la relación entre capital, raza y nación.

Las discusiones acerca del matrimonio como piedra fundacional de la sociedad, tuvieron lugar en Argentina a lo largo de todo el siglo y bajo las dinámicas que cada época propuso política y socialmente. Durante el
Centenario de la Revolución de Mayo, se llevaron adelante una serie de congresos y reuniones prestigiosas para debatir los alcances de la modernidad en las coordenadas criollas. En este contexto, ubicamos tanto al "Primer Congreso Patriótico de Señoras" como al "Primer Congreso Femenino internacional". Con público diferente, estos eventos trabajaron acerca de varias cuestiones que generaban discusiones acaloradas y hasta irreconciliables refiriendo a ejes como el matrimonio y el papel de la mujer en la sociedad. Progresistas y católicas discutieron acerca de los artículos del Código Civil que regulaban el matrimonio y los derechos gananciales de las mujeres. ${ }^{8} \mathrm{Si}$ bien, no es el tema de este artículo, esos debates nutrieron una serie de posturas y consensos acerca de los roles establecidos tanto como de los derechos privados y públicos de las mujeres. Aquí emerge el matrimonio como uno de los puntos más conflictivos.

Como ha mencionado Marcela Nari, la eugenesia como ciencia práctica siempre fue cercana a la política y en el caso argentino, a esta cercanía, se sumaba la fuerte influencia de la Iglesia Católica. ${ }^{9}$ Tal conglomerado nos lleva a pensar que allí estuvieron las raíces de la aceptación de la eugenesia "positiva" es decir de no intervención directa sobre los cuerpos, que tuvo lugar en el país. De tal modo, el acento puesto en la eugenesia de "selección" y

8.Para profundizar esta problemática, se sugieren los exhaustivos trabajos de Dora Barrancos: BARRANCOS, Dora, Inclusión/exclusión. Historia con mujeres,

Fondo de Cultura Económica, Buenos Aires, 2001; BARRANCOS, Dora, Mujeres en la Sociedad Argentina. Una bistoria de cinco siglos, Sudamericana, Buenos Aires, 2007.

9. NARI, Marcela, Politicas de maternidad y maternalismo político. Buenos Aires, 1890-1940, Biblos, Buenos Aires, 2004. 
"transformación" se propuso como respuesta al "caos" poblacional -en términos de "raza"- que vivía el país. El interrogante estuvo centrado en buscar dinámicas que hicieran permeables las políticas eugenésicas desde los claustros hasta los hogares. Aquí los medios de comunicación jugaron un papel fundamental. La información debía estar dirigida hacia "la mujer", como principal protagonista de esta cuestión.

De esta información dependía el desarrollo del hecho social y político de la maternidad, pensado desde una cuestión eugénica. Sin embargo, existían una serie de mecanismos dispuestos para ejercer un control sobre la potenciabilidad de una pareja a la hora de transformar el compromiso humano en acuerdo legal.

La "degeneración de la raza" fue concebida como un peligro inminente. Los debates en torno al proyecto de ley de profilaxis de enfermedades venéreas contenía a dos imágenes sociales creadas acerca de "la mujer": la pública y la del hogar. ${ }^{10}$ Esta cuestión que parecía una extrapolación del binomio fundacional de la literatura argentina: civilización y barbarie, tomaba forma de ley ya que sobre ambos cuerpos se legislaba. La prostitución pasó así, a ser el eje de los males venéreos que amenazaban el orden de los hogares. La sanción en 1936 de la ley 12.331 prohibió el establecimiento de casas donde se ejerciera la prostitución, aboliendo el criterio

10. Abordados de manera muy concisa por GRAMMATICO, Karen, "Obreras, prostitutas y mal venéreo. Un Estado en busca de la profilaxis", en GIL LOZANO, Fernanda, PITA, Valeria e INI, María Gabriela (directoras) Historia de las mujeres en la Argentina. Siglo XX, Taurus, Buenos Aires, 2000. También por: MIRANDA, Marisa, Controlar 10 incontrolable. Una historia de la sexualidad en Argentina, Biblos, Buenos Aires, 2011. reglamentarista que se había iniciado en 1874 en la ciudad de Rosario con una inmediata recepción en el resto del territorio nacional. ${ }^{11}$ Así el Estado, avalado por una conjunción de discursos políticos, morales y científicos, planteó la preocupación por la proliferación de enfermedades venéreas, sancionando el "deber ser" de las mujeres y con ello el matrimonio como un punto a reforzar para "mejorar la raza". ${ }^{12}$

Considerada como base fundamental de la familia -en el marco de un país donde la Iglesia Católica marcó su impronta en aspectos políticos y culturales- , la unión legal implicaba una serie de mecanismos desde donde se establecían parámetros antropométricos, que designaban la capacidad genésica de los futuros contrayentes. Aquellos a quienes estos parámetros biotipográficos no alcanzasen, se constituían en parte del peligro conspirativo que amenazaban el orden social ideado.

Las notas que abundaban en los diversos números de la publicación referían a la formación del matrimonio como un proceso, signado por el hábito constante de la selección. Este mecanismo, aparecía discursivamente, como natural a la condición humana, es decir,

11. Sobre la cuestión de la prostitución reglamentada en el ámbito urbano, referimos al complejo y amplio trabajo que realizó la Dra. María Luisa Múgica, donde se da cuenta de las dinámicas de la prostitución reglamentada en Rosario como modelo fundacional que será tomado en el resto del país. MÚGICA, María Luisa, La ciudad de la Venus impúdica. Rosario, historia y prostitución. 1874/1932, Laborde Editor, Rosario, 2014.

12. Acerca de las sanciones a los cuerpos, las sexualidades y las prácticas de cada época podemos citar el último trabajo editado por BARRANCOS, Dora, GUY, Donna y VALOBRA, Adriana (editoras) Moralidades y comportamientos sexuales. Argentina 1880-2011, Biblos, Buenos Aires, 2014. 


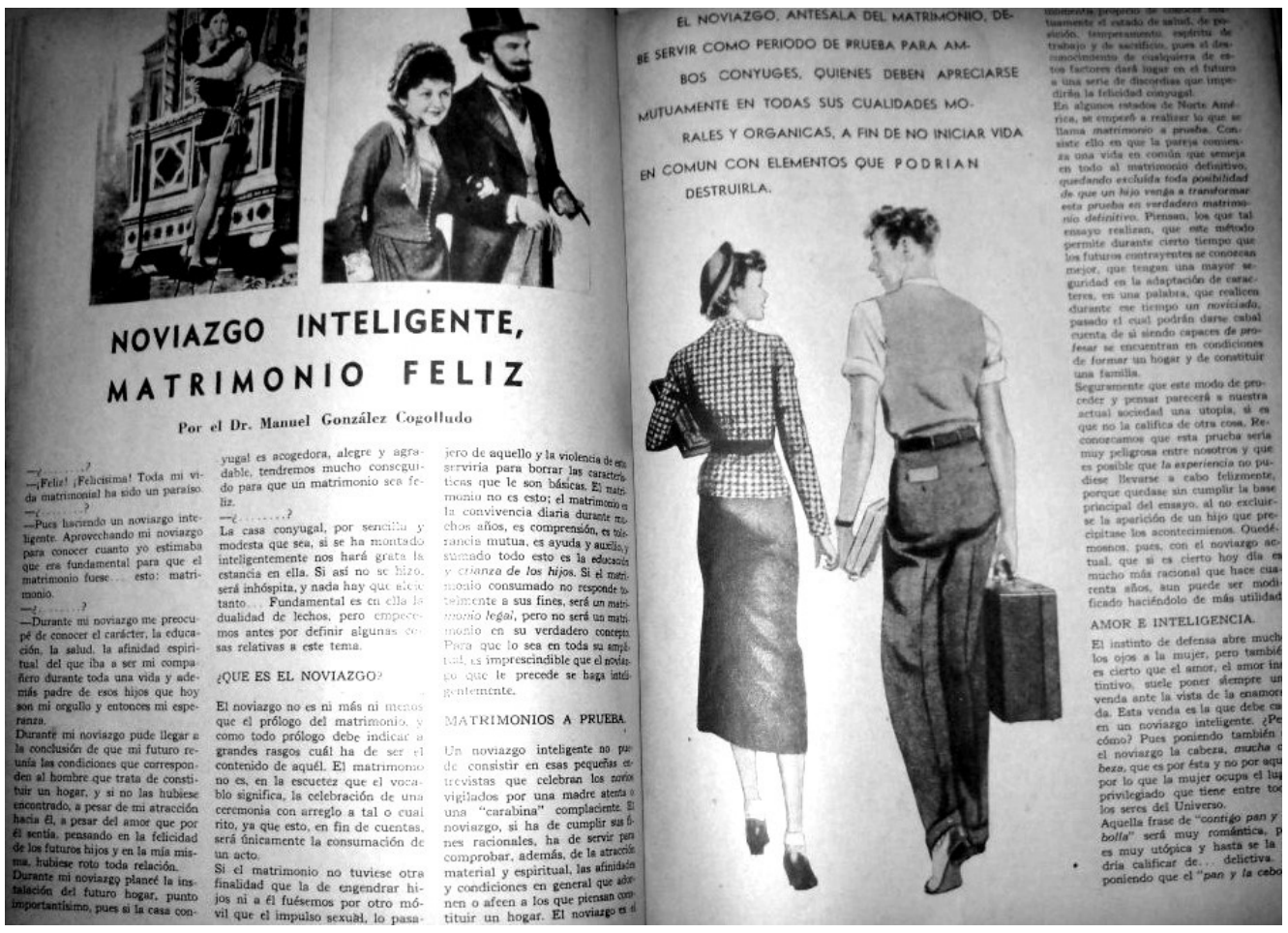

Imagen 1. "Noviazgo Inteligente, matrimonio feliz". Fuente: González Cogollardo, Manuel, "Noviazgo Inteligente, matrimonio feliz", en Viva Cien Años, Buenos Aires, enero de 1940, V.VIII, año 6, No 7, pp. 454-455.

como parte del instinto propio de supervivencia. Esta selección de los candidatos adecuados, estaba íntimamente relacionada con la concepción del deseo de lo bueno, lo sano y lo fuerte. Estas tres dimensiones de la condición humana aparecían en $V C A$ como parte del "deber ser" también -y fundamentalmenteen este proceso selectivo de pareja. Las notas llevaban siempre títulos persuasivos, que interpelaban a la lectora (o lector) y señalaban a tres variantes: la consecución de un noviazgo consciente de la herencia fuerte, un noviazgo improvisado con la probabilidad de educar en las ventajas del mejoramiento racial y un tercer tipo de noviazgo, producto de la ignorancia de los factores de herencia biológica y conducta social. Contra este tercer tipo de relación se establecía una campaña para que las mujeres, ya fueran las protagonistas del mismo, las madres de alguna de las partes o personas cercanas a los vinculados, ejercieran su deber de comunicar e instar a los novios acerca de la necesidad de realizar una visita a la asistente de higiene o al eugenista. Las operaciones discursivas para describir a cada una de las situaciones siempre involucraban estrategias 
tendientes a generar empatía con alguno de los protagonistas, por parte del lector. Los títulos de los artículos eran directos, breves, concisos y buscaban interpelar a quien los leía. Veamos algunos ejemplos:
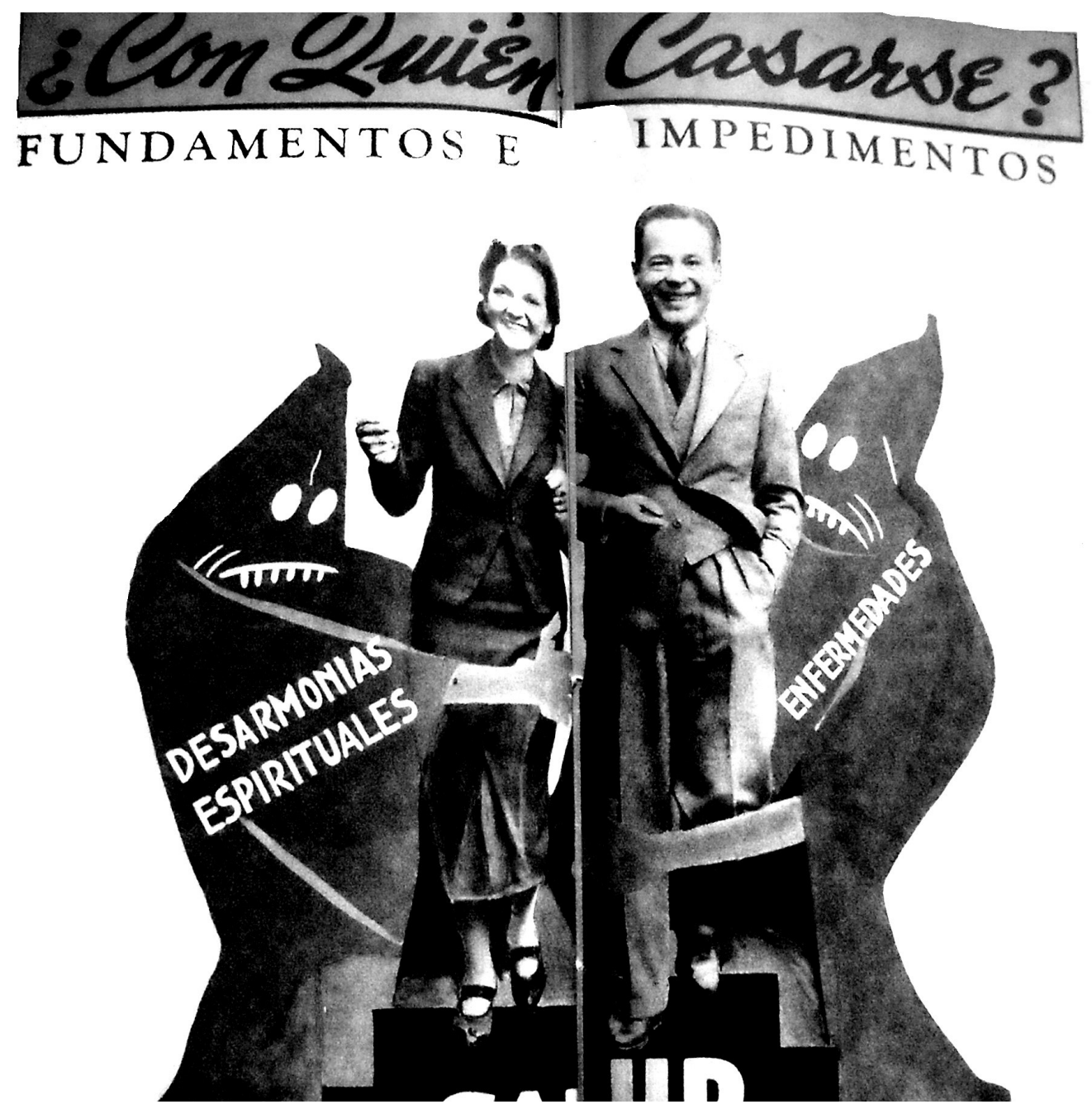

Imagen 2. “Con quién casarme? Fundamentos e impedimentos.” Fuente: Benthin, D, “¿Con quién casarme? Fundamentos e impedimentos.”, en Viva Cien Años, Buenos Aires, agosto de 1937, V. III, año 5, No 11, pp. 722-724. 


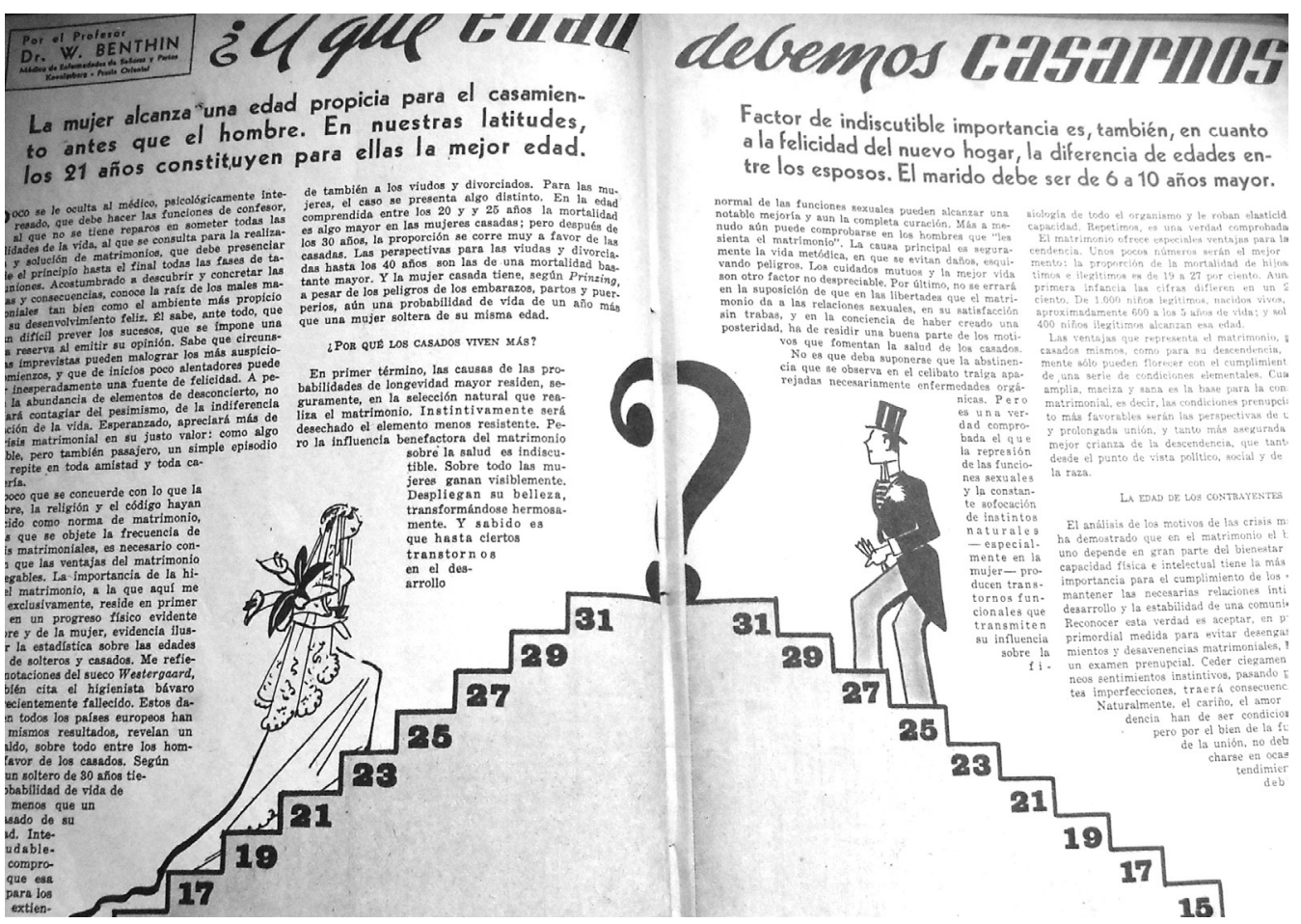

Imagen 3. “¿A qué edad debemos casarnos?”.Fuente: Benthin, D., “¿A qué edad debemos casarnos?”, en Viva Cien Años, Buenos Aires, septiembre de 1937, V. III, año 5, No 12, pp. 798- 801.

\section{Matrimonios y algo más...}

El matrimonio no estaba vinculado a la capacidad reproductiva, sino a la calidad de los caracteres heredables de los esposos en cuestión. En la década de 1930, el énfasis de la búsqueda genésica pasaba por la introducción, como vimos anteriormente, de ciertos cambios medioambientales. En esta lógica, la elección de los contrayentes era vital. La difusión del ideario referido a este punto se realizó con detalles variados. Siempre el consejo médico exponía los posibles peligros de engendrar vida por fuera de la norma eugénica. Respetando la pauta editorial de la publicación, estos consejos enfrentaban el tema de manera directa y bajo un lenguaje sencillo y siempre mediante enunciados tendientes a alarmar acerca de diversas cuestiones que se presentaban a la hora de jerarquizar las potenciales parejas. Por ejemplo: ¿Es en realidad tan grave la cosa como la pintan? ¿Corre peligro la salud de los hijos de matrimonios consanguíneos? ${ }^{13}$

13. ALZUA, Mario, $V C A$, Buenos Aires, febrero 1937, V. III, No 5, pp. 308-310. 


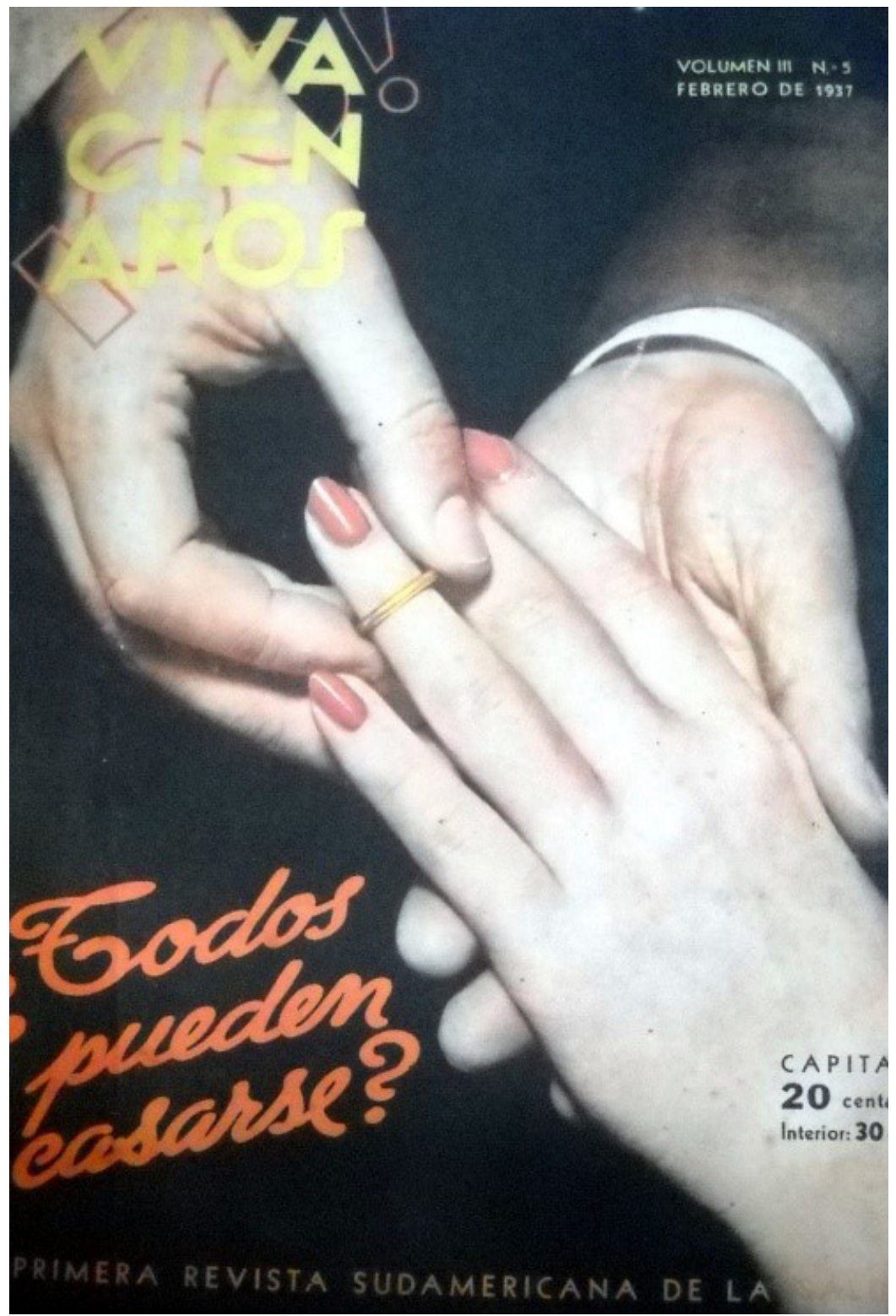

Imagen 4. “'Todos pueden casarse?. Fuente: González Cogollardo, Manuel, "Noviazgo Inteligente, matrimonio feliz", en Viva Cien Años, Buenos Aires, febrero de 1937, V.III, año 4, No 5, pp. 308-310. 
Esta pregunta presente en el artículo analizado, intentaba generar con el lector, un guiño acerca de la legitimidad científica de algunas cuestiones presentes en la cultura popular. A continuación el Dr. Alzua, se encargaba de demostrar científicamente los riegos que emanaban de forma inequívoca, del matrimonio consanguíneo. Repasando diversas enfermedades de carácter hereditario, el mismo médico concluía en que la palabra del profesional de la salud, no equivalía a la última voz respecto de la totalidad de la pregunta: “'Todos pueden casarse?”. Es decir, la voluntad del deseo de los individuos siempre es mayor al llamado eugenésico a contribuir con el "mejoramiento racial", sin embargo su juicio sobre la potencialidad de la pareja no dejaba de considerar el factor del azar. Es por esta cuestión que los matrimonios que se conformarían conscientes del proceso de identificación, clasificación, jerarquización y exclusión alcanzarían con holgura los cánones impuestos por el examen prenupcial realizado, siguiendo la ley nacional 12.331. Dicho proceso de selección contenía, en sí mismo, elementos de orden azaroso, contra los cuales la eugenesia, no podía disponer ninguna de sus herramientas de prevención. Es por ello que se intentaba establecer la necesidad de reducir la presencia de patologías y riesgos, generando mapas genealógicos con la información de las familias de los esposos. La avidez de difusión acerca de los cuidados del "capital genésico" de la población se traducía en una serie de fichas donde el lector podía completar las ramas de árbol genealógico de su pareja y propio, donde aparecían datos como nombre, apellidos, edad, enfermedades, causa de defunción, etc. La estadística, el examen prenupcial y el consejo del médico eugenista, hacían a la elaboración de esa "conciencia higiénica" respecto de la herencia.
Las preocupaciones de los novios, según esta publicación, debían centrarse en combinar amor, inteligencia y herencia de caracteres de manera tal que se produjera el fortalecimiento de los cuerpos individuales en beneficio del "ser nacional" que estaban pensando los eugenistas, dentro del clima de ideas de la década del '30.

No podemos elegir a nuestros padres.

No podemos elegir ese sello, esa marca de fábrica, que se llama temperamento, la "constitución". Podemos cambiar el apellido; las enfermedades que heredamos de nuestros padres no las podemos cambiar por la salud, pero sí podemos elegir el ser con quien contraemos matrimonio. ${ }^{14}$

La exclusión de aquellos que no se consideraban material genésico deseable, se establecía también desde el matrimonio. Existían quienes no deberían casarse, que si bien tenían derecho adquirido, no poseían legitimidad para la unión debido a patologías propias, que eran transmisibles hereditariamente a las futuras generaciones. La ley nacional ya mencionada de profilaxis de enfermedades venéreas imponía el examen médico prenupcial como mecanismo por el cual los individuos se sometían a una serie de controles del poder médico sobre sus cuerpos. De padecer una enfermedad infectocontagiosa, ese derecho a la unión conyugal se veía revocado, en tanto estuviera presente la enfermedad que pusiera en peligro la potencial descendencia de la pareja. Dicha ley se establecía como herramienta para ejercer el control sobre las enfermedades venéreas y los cuerpos que estas ponían en peligro. En su artículo número 3 , hacía explícita la necesidad de abordar las patologías de orden venéreo no solo como problema médico, sino como

14. Ídem, p. 309. 


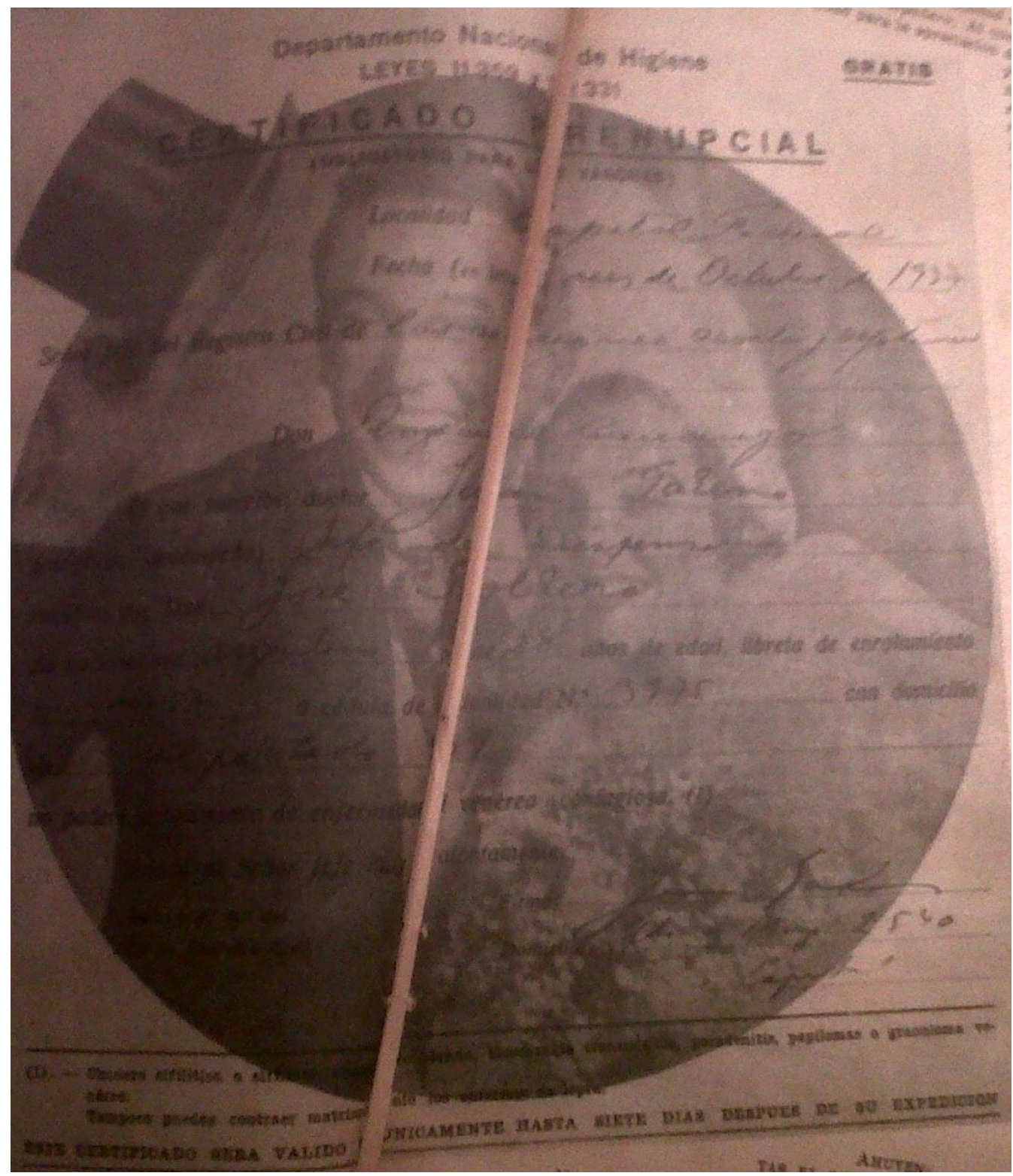

Imagen 5. "Certificado médico prenupcial" Fuente: Viva Cien Años, Buenos Aires, octubre de 1937, V.IV, año 5, No 1.pp. 6-7 
problema social. Para ello se incentivaba la difusión y divulgación científica de medidas sanitarias tendientes a informar acerca de los peligros que estas enfermedades encarnaban en el cuerpo social. Así también, proponía la hospitalización forzada de aquellos en quienes se detectara una enfermedad de este tipo siendo obligación reportar tales males.

Aquellas parejas que no conseguían el certificado de aprobación del examen prenupcial se encontraban inhabilitadas legalmente para realizar la unión civil. En primer término, este examen estaba dispuesto solo para los varones mayores de edad, más luego las mujeres también fueron obligadas a realizarlo. En caso de ser portador de alguno de estos males venéreos y contagiar a otra persona, se consideraba que se quebraba la ley, dado el inciso que refería a la obligatoriedad de la comunicación de su condición: su omisión era considerada delito. Si bien esta ley era de carácter nacional, fruto de intensos debates en el seno del Congreso, cada delegación municipal y provincial realizó diversas adaptaciones de la misma a los mecanismos sociales de cada lugar. ${ }^{15} \mathrm{Si}$ bien el certificado de examen médico prenupcial es era obligatorio para casarse en cualquier juzgado de paz del país, aquel ítem que estipulaba a la prohibición de la actividad prostibularia, respondía necesariamente a la idiosincrasia de cada uno de los lugares del interior. Como estos manejasen la abolición de las casas de tolerancia, era parte de la flexibilidad que permitía la ley. Los cuerpos femeninos eran, en este caso, considerados los canales de contagio y difusión de las patologías venéreas. Estas, además de ser un problema de orden médico, se constituían, desde su inicio, en

15. Parte de estos debates se ven reflejados en: "Proyectos presentados por el Dr. Padilla”, Congreso Nacional, Diario de Sesiones de Diputados, 30 de mayo de 1934, pp. 662-3. parte del problema social. Como tal cargaban con la estigmatización y la construcción social del contagio. Las mujeres, los homosexuales y las minorías eran aquellos en quienes se imponía el peso de ser permeables al contagio. Pensemos que para las décadas del '30 y '40, la sífilis era considerada una patología que preocupaba a la elite dirigente. ${ }^{16} \mathrm{La}$ exclusión de los enfermos sifilíticos, era parte de la condena moral que acompañaba los pesares de la patología física.

Las enfermedades venéreas conspiraban contra el orden social ideado por parte de los médicos que se formaron a la luz del higienismo y ahora subían la apuesta a partir de la eugenesia, como parte de la preocupación poblacional.

Desde los más diversos sectores políticos se coincidía en la necesidad de poner el acento en los peligros encarnados por el contagio y la necesidad de vigilar y controlar la expansión de estos males, vigilando a los cuerpos femeninos. Para ello era necesario llegar al seno del hogar y con eso a "la mujer" lectora, quien debía ser consciente de los "peligros" a los que podía exponer a todo el cuerpo social a través de una serie de decisiones.

Las propuestas de estudio eugenésico casero, incluían, como vimos, la confección de su propio registro de árbol genealógico, pero también es interesante detenernos en los cuestionarios que confeccionaban eugenistas, para interpelar a los contrayentes. Estos

16. Para profundizar esta idea podemos citar el trabajo de Susana Belmartino y Diego Armus acerca de las décadas de 1930 y 1940 en relación a la corporación médica y la preocupación sanitaria: ARMUS, Diego y BELMARTINO, Susana, Enfermedades, médicos y cultura higiénica, Sudamericana, Buenos Aires, 2001, p. 288. 


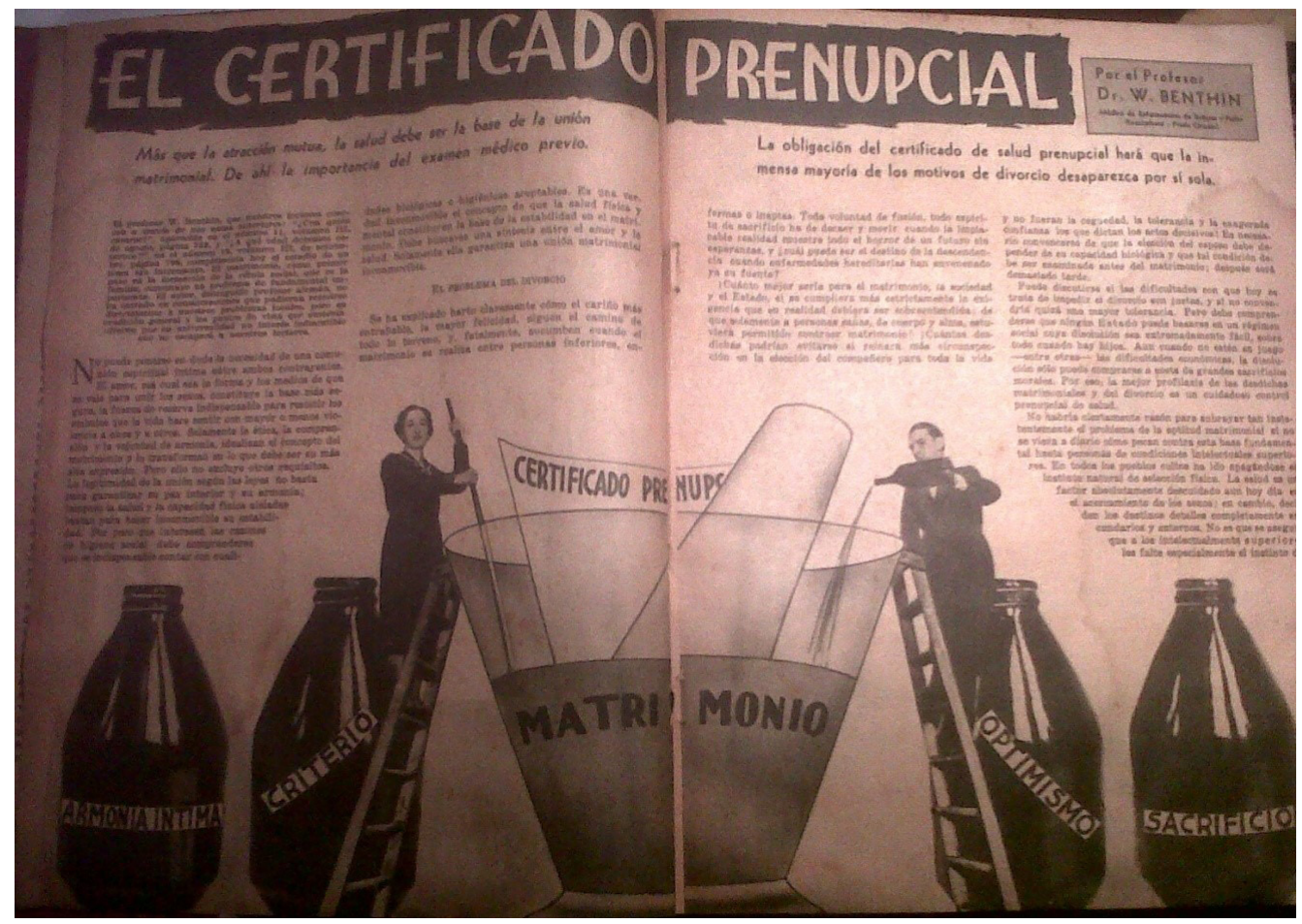

Imagen 6. "Certificado Prenupcial" . Fuente: Viva Cien Años, Buenos Aires, octubre de 1937, V.IV, año 5, No 1. pp. 8-9.

cuestionarios se publicaban todos los años, bajo diferentes formas en la revista, pero respetaban siempre la matriz de datos de diverso orden.

La confección de estos cuestionarios estaba vinculada con una encuesta que generaba la revista entre médicos de distinta perspectiva política, coincidentes en la necesidad de difundir la teoría de la eugenesia y el importante papel del matrimonio y la herencia, para el desarrollo de la misma. Estos cuestionarios fueron resueltos por más de diez profesionales de la salud, a lo largo de los números del séptimo año de la revista.
Hacían visible el objetivo de legitimar las políticas de regulación del matrimonio con fines eugénicos. Las preguntas que respondían estas figuras del campo académico eran diez y cada una de ellas, entrelazaba conceptos generando la sensación de la necesidad de evaluar las tendencias hereditarias entre los contrayentes. ${ }^{17}$ Es evidente que existía una

17. Cuestionario realizado a Rezzano, Clotilde;

Osorio y Gallardo, Ángel; Krapf, Eduardo, entre otros profesionales de la salud y juristas. Preguntas realizadas en las ediciones del año 1940 Cuestionario. 1. ¿Qué condiciones mínimas de salud física hacen falta para el matrimonio? 2. ¿Qué resultados dan según su opinión los casamientos fruto de un amor apasionado? ¿Y los 
preocupación por incentivar una especie de conciencia acerca de que no solo los factores hereditarios, sino cuestiones ambientales vinculadas a la pertenencia a determinado grupo social desde el contexto mismo de la publicación- eran parte fundamental en la toma de decisiones particulares que afectaran al cuerpo social.

El noviazgo inteligente así como el matrimonio armónico, respondían a una serie de criterios establecidos según parámetros higienistas y eugenésicos. Aquí, las operaciones discursivas eran variadas, como vimos anteriormente, $\mathrm{y}$ siempre apelaban a dos elementos claves para entender los mecanismos de penetración dentro del discurso social de la eugenesia coercitiva disimulada: el carácter de consejo, seguido por el aval técnico brindado por la ciencia.

Desde cuestionarios, hasta pruebas caligráficas, se realizaban a la par de los

forjados por la familia sin que intervenga la voluntad de uno o de los dos cónyuges? ¿YY los realizados por cálculo o conveniencia con el consentimiento de la familia?- 3. ¿Puede usted, citar ejemplos representativos? 4. ¿Qué papel tiene en la felicidad del matrimonio la conformidad de la familia? ¿Y la desigualdad o igualdad de clase social? ¿y las diferencias o semejanzas de educación y cultura? ¿Y el posible advenimiento futuro de los hijos? 5. ¿Es importante el factor económico al considerar al matrimonio? ¿Y la profesión del marido? ¿y de la mujer? 6. ¿Qué opina del factor erótico en la elección del cónyuge? 7. ¿Cómo conocer durante el trato prematrimonial las incompatibilidades temperamentales o de carácter? 8. ¿Los intereses y aficiones distintas son un verdadero obstáculo para la armonía conyugal? $¿ Y$ las diferencias de nacionalidad? ¿Y las de religión? ¿Y las de edad? ¿y los contrastes físicos? 9. ¿Qué opina Usted sobre los amores que comienzan en la infancia o en la adolescencia? 10. ¿Qué papel asigna Usted a la coeducación de sexos en la educación de la pareja? ¿Debe educarse a hombres y mujeres para el matrimonio?¿Cómo? exámenes médicos requeridos por el certificado. La elección matrimonial estaba fundada en fines específicos de reproducción consciente y educación eugenésica de las futuras generaciones. Así el "éxito social" de la unión matrimonial se traducía en el estado de obligación de los contrayentes para con la especie. La idea de una descendencia "sana, fuerte que contribuya al engrandecimiento de la patria" era vital para entender los términos y las secciones que utilizaba la publicación a la hora de tratar el tema del matrimonio y la familia. ${ }^{18}$

Una vez iniciado el matrimonio, los consejos aludían a la responsabilidad de "la mujer" en la consolidación de esa unión. Los cuidados podían clasificarse según tres ejes: del hogar, de los hijos y del marido. Respecto a este último, la principal advertencia que se le realizaba a "la mujer" tenía que ver con la prevención de los excesos, producto de las pasiones. Tal vez, sobre este punto hubiera una clara coincidencia entre la noción de matrimonio eugénico con la noción clásica de matrimonio de la Iglesia Católica. Las coincidencias eran más que evidentes a la hora de abordar las sexualidades de los contrayentes y la responsabilidad de "la mujer" de retener a su marido a través del respeto al acuerdo conyugal, evitando el exceso. Muchos de los autores de las notas relacionadas al matrimonio y la sexualidad, escribían en publicaciones académicas y boletines, esas ideas radicalizadas. En ellas se observaba una marcada relación entre Iglesia Católica y "mejoramiento racial" con enunciados

18. Para consular un esquema general sobre matrimonio y familia referido al caso de la revista en Viva Cien Años se puede consultar el artículo de VEZZETTI, Hugo, "Viva Cien Años: Algunas consideraciones sobre familia y matrimonio en la Argentina”, en Punto de Vista, Buenos Aires, 1985, Año XI, № 27. 


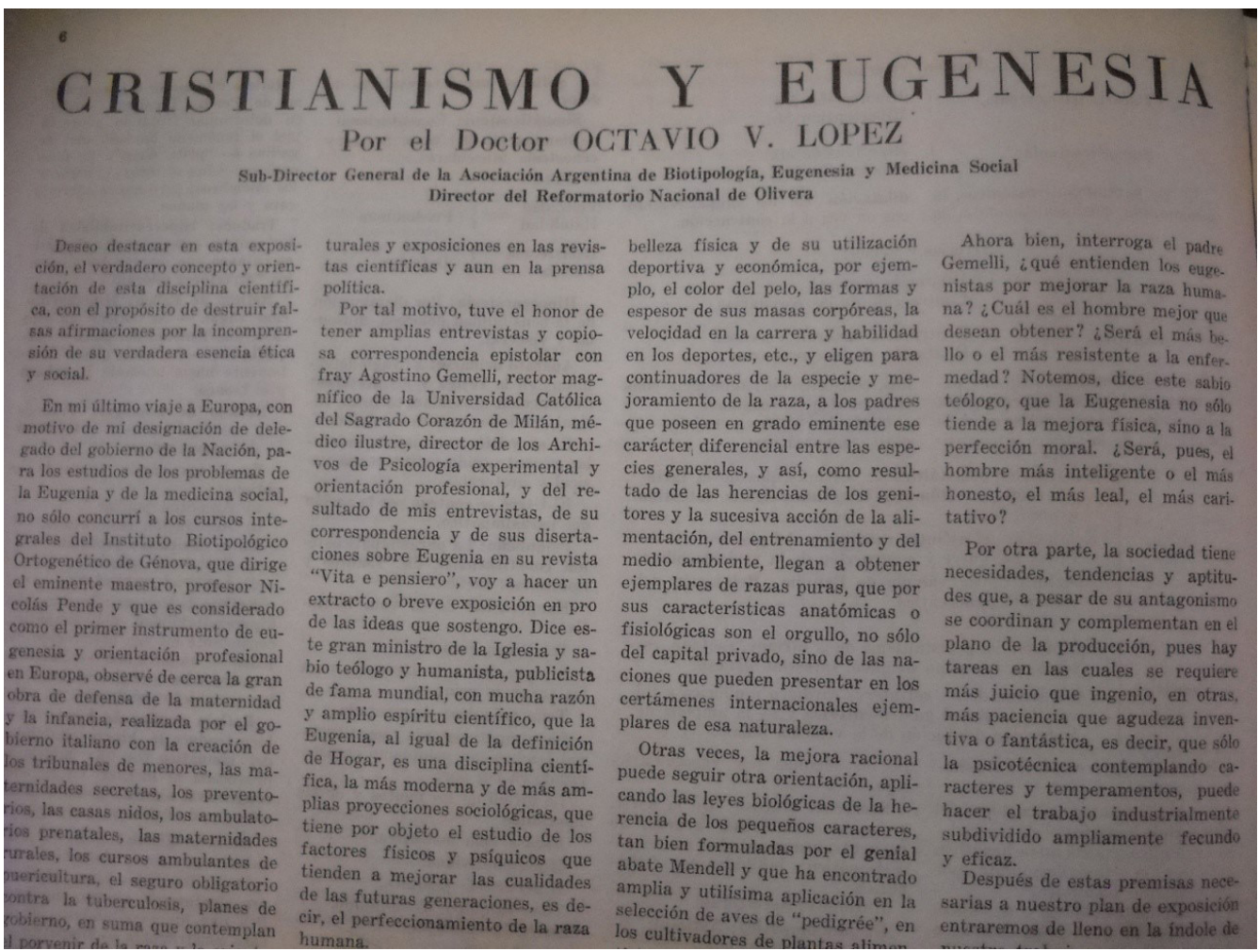

Imagen 7. "Cristianismo y Eugenesia”. Fuente: López, Octavio: "Cristianismo y Eugenesia", en Anales de Biotipología, Eugenesia y Medicina Social, Buenos Aires, agosto de 1936, año III. No 9, p. 6.

mucho más duros que los que se reflejaban en $V C A$. La vinculación entre la iglesia y la publicación se manifestaba, como ya dijimos, en el tratamiento de los temas y en quienes los abordaban. Referentes de distintos organismos dedicados a la salud en América Latina como los directivos de $A B E M S$ escribían en $V C A$ de manera cotidiana. La estrategia discursiva fue novedosa. El público a quien estaba dirigido el boletín de $A B E M S$, era radicalmente diferente. En él, se escribía para colegas de variados puntos del país y del continente, refiriéndose a los viajes y aprendizajes, así como a los últimos estudios e informes sobre medicina preventiva y eugenesia. El círculo de influencias cruzadas podría ser entrelazado en esta publicación y en su reflejo en el proyecto de divulgación popular de saberes científicos e higiénicos.

Retomando la cuestión de la sexualidad dentro del matrimonio, respecto a los deberes de los cónyuges, el clima de la época legitimaba el discurso desde saberes normativos, como la medicina, pero también desde la religión, ya 
que era clara la influencia sobre la sanción de valores morales en las prácticas conyugales, emanadas de la Encíclica Casti Connubbi, llevada adelante por Pío XI en 1930. ${ }^{19}$

El mundo de los excesos, afectaba tanto a "la mujer" como al hombre. Es este último, el que caía una y otra vez en la infidelidad, lo cual atentaba y ponía en peligro el cuerpo social,dada la proliferación de enfermedades venéreas que, mediante tales prácticas, entraban en el seno del hogar. La problematización de la situación recaía en "la mujer", como responsable del dominio de las pasiones de su esposo. Los celos, como momento de cuestionamiento, parecían ser parte del ajuar recibido por las mujeres a la hora de contraer matrimonio. Cuando se producía el caso contrario y era "la mujer" la que cometía la infidelidad, la revista dirigía las responsabilidades al cuerpo femenino que no había resuelto los avatares de la "coquetería excesiva" o alguna conducta patológica de "la mujer".

Volviendo a los cuidados dispuestos en la publicación VCA, respecto al hogar, estos estaban relacionados a las prácticas modernas y las formas establecidas para resolver los problemas propios del ingreso de nuevos mecanismos de consumo en los hogares. Fueron numerosas las operaciones discursivas sobre este punto. La más llamativa era aquella que abordaba las autoevaluaciones de "la mujer" sobre el cuidado del hogar. Una serie, en principio, de consejos sobre actividades y problemas a resolver en la vida diaria dentro del hogar y, más tarde, una evaluación con situaciones hipotéticas y preguntas. Luego de cotejar, en el número siguiente, las respuestas

19. Trabajado por MIRANDA, Marisa, Controlar lo incontrolable..., Op.Cit. dadas con las soluciones propuestas por los profesionales, "la mujer" podía concluir acerca del grado de manejo de los cuidados del hogar que poseía.

Las habilidades en las que se basaba la premisa "de la buena ama de casa", radicaban en colocar clavos, limpiar manchas, quitar rastros de grasa de la ropa, ventilar el hogar, hacer cálculos para economizar gastos, realizar manualidades útiles a la vida en el hogar, etc. Resolver estas cuestiones sin la presencia del hombre mostraba, por un lado, independencia de "la mujer eugénica", y por el otro, respeto a la función social del hombre fuera del hogar. El hogar, como ya dijimos, constituía un espacio de disfrute y comodidad, por lo menos para el hombre y los niños. La transformación técnica del hogar, debía ser parte de los deberes que "la mujer" asumía al contraer matrimonio. Estar pendiente de la introducción de nuevas prácticas, hacía también a su función dentro del esquema eugénico del hogar.

La felicidad del matrimonio se traducía en el éxito social y biológico del mismo. Sobre las espaldas del hombre recaía otorgar las condiciones materiales apropiadas para formar y mantener a la familia; de "la mujer" dependería el resto. Es decir, todos aquellos hilos que entrecruzaban las variables propias de las relaciones humanas dependían de los cuidados femeninos hacia los elementos que componían el matrimonio y la familia.

\section{A modo de cierre}

"Pero nos dice la ciencia también: así como esos impulsos deben satisfacerse en el normal; y así como en muchos casos el llevarlos a cabo constituye una terapéutica, 


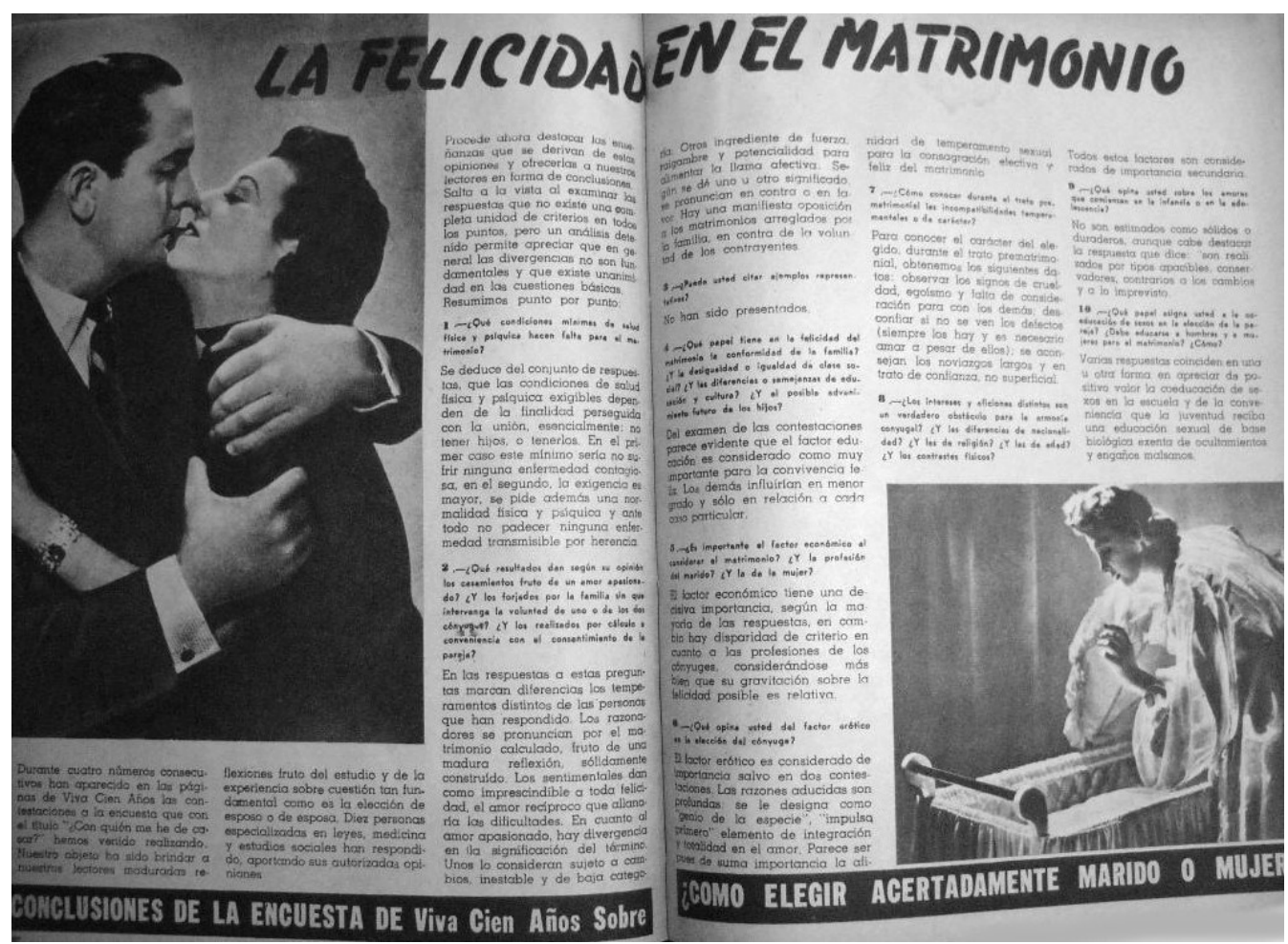

Imagen 8. "La felicidad en el matrimonio. Conclusiones de la encuesta de Viva Cien Años ¿Cómo elegir acertadamente marido o mujer?” Fuente: Viva Cien Años, Buenos Aires, noviembre de 1941, V.X, año 7, No 6, pp.390-391.

un tratamiento eficícalisimo, existen otros en quienes están vedados por completo. Los que no deben casarse jamás”. ${ }^{20}$

Los deberes y cuidados, por parte de las mujeres -según pensaba la eugenesia en Argentina-, de sus maridos y hogares se traducía en funciones sociales que, a partir de las pautas eugénicas, llevaban la felicidad y el éxito a la

20. ALZUA, Mario, VCA, Buenos Aires, febrero 1937, V. III, No 5, pp. 308-310.

106 pareja y con ella al cuerpo social. El matrimonio selectivo, conllevaba la optimización de las variables heredables y ambientales, eliminando elementos azarosos que podían perjudicar el devenir de la "raza". Ese era el discurso de $V C A$ respecto al matrimonio y el conjunto de responsabilidades que el mismo involucraba. Fuera de los elementos de orden administrativo y médico como certificados prenupciales (que se iniciaron con la ley 12.331 y siguen hasta nuestros días), estudios y estadísticas 
biotipológicas, existieron sanciones morales $\mathrm{y}$ éticas emanadas de saberes normativos e instituciones relacionadas a la fe católica, que proponían también que la sociedad fuera un reflejo de la familia, así como que los cuerpos individuales reflejaran el cuerpo social en su conjunto. Es posible afirmar que existieron tanto un clima de época favorable como discursos ligados entre sí, que fueron formando cadenas dialógicas para poner en marcha y legitimar prácticas propias de la eugenesia de carácter coercitivo y de intervención simbólica.

Así los componentes "deseables" de la herencia de caracteres tenían en este marco discursivo de mediados de los treinta, oportunidad de mejorar el conjunto social todo. Aquello que escapaba de esta norma y de la "receta" para el matrimonio perfecto, era "lo no deseable", lo cual por no ser apto en su carácter genético, se transformaba en aquello a lo que no debíamos unirnos. El "otro" que ponía en peligro el ideario de pueblo sano y fuerte.

Obviamente la realidad indica que los esfuerzos por vincular discursos que tenían una fuerte influencia social dada por su legitimidad como miembros de la comunidad -médicos, profesionales, miembros de la Iglesia- fueron muchos. Si bien, los comportamientos poblacionales escapaban al recetario propuesto, muchas de las medidas emanadas de propuestas eugenésicas, siguen vigentes hasta nuestros días.

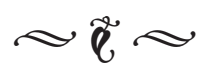

Recibido: 20 - 05 - 2015

Aceptado: 19 - 10 - 2015

Publicado: 30 - 06 - 2016 


\section{Bibliografía}

ARMUS, Diego y BELMARTINO, Susana, Enfermedades, médicos y cultura higiénica, Sudamericana, Buenos Aires, 2001.

BARRANCOS, Dora, Inclusión/exclusión. Historia con mujeres, Fondo de Cultura Económica, Buenos Aires, 2001; .

BARRANCOS, Dora, Mujeres en la Sociedad Argentina. Una historia de cinco siglos, Sudamericana, Buenos Aires, 2007.

BARRANCOS, Dora, GUY Donna y VALOBRA, Adriana (editoras) Moralidades y comportamientos sexuales. Argentina 1880-2011, Biblos, Buenos Aires, 2014.

DE DIEGO, José Luis (director) Editores y politicas editoriales en Argentina (1880-2000), Fondo de Cultura Económica, Buenos Aires, 2006.

GRAMMATICO, Karen, "Obreras, prostitutas y mal venéreo. Un Estado en busca de la profilaxis”, en GIL LOZANO, Fernanda, PITA, Valeria e INI, María Gabriela (directoras) Historia de las mujeres en la Argentina. Siglo XX, Taurus, Buenos Aires, 2000.

GUTIERREZ, Leandro y ROMERO, Luis Alberto, Sectores populares, cultura y politica, Sudamericana, Buenos Aires, 1995.

LINARES, Luciana, Delineando los cuerpos. Construcciones discursivas en torno a la mujer a través de la propaganda eugénica en Argentina. El caso de la publicación Viva Cien Años. 1935-1947, Tesis de Maestría, Universidad Nacional de Mar del Plata, 2014.

MIRANDA, Marisa, Controlar lo incontrolable. Una historia de la sexualidad en Argentina, Biblos, Buenos Aires, 2011.

MIRANDA, Marisa, "La Argentina en el escenario eugénico internacional” en MIRANDA, Marisa y VALLEJO, Gustavo (directores) Una Historia de la eugenesia. Argentina y las redes biopoliticas internacionales. 1912-1945, Biblos, Buenos Aires, 2012.

MÚGICA, María Luisa, La ciudad de las Venus impúdicas. Rosario, bistoria y prostitución. 1874/1932, Laborde Editor, Rosario, 2014. 
NARI, Marcela, Politicas de maternidad y maternalismo politico. Buenos Aires, 1890-1940, Biblos, Buenos Aires, 2004.

PALMA, Héctor, "Consideraciones historiográficas, epistemológicas y prácticas acerca de la eugenesia", en MIRANDA, Marisa y VALLEJO, Gustavo (compiladores) Darwinismo social y eugenesia en el mundo latino, Siglo Veintiuno, Buenos Aires, 2005.

SIDICARO, Ricardo, La politica mirada desde arriba. Las ideas del diario La Nación. 1909- 1989, Sudamericana, Buenos Aires, 1994.

STEPAN, Nancy, A hora da Eugenia. Raça, género y nación no América Latina, Fiocruz, Río de Janeiro, 1991.

VEZZETTI, Hugo, "Viva Cien Años: Algunas consideraciones sobre familia y matrimonio en la Argentina”, en Punto de Vista, Buenos Aires, 1985, Año XI, No 27. 